\title{
Ventromedial Thalamic Neurons Convey Nociceptive Signals from the Whole Body Surface to the Dorsolateral Neocortex
}

\author{
Lénaïc Monconduit, Laurence Bourgeais, Jean-François Bernard, Daniel Le Bars, and Luis Villanueva \\ Institut National de la Santé et de la Recherche Médicale U-161, 75014, Paris, France
}

The somatosensory properties of ventromedial (VM) thalamic neurons were investigated in anesthetized rats by examining their responses to calibrated cutaneous stimuli. A population of neurons within the lateral part of the ventromedial thalamus (VM/) showed two peaks of activation after percutaneous electrical stimuli, regardless of which part of the body was stimulated. The early and late peaks were elicited by $\mathrm{A} \delta$ - and $\mathrm{C}$-fiber activities with mean conduction velocities of $12.9 \pm 0.9$ and $1 \pm$ $0.2 \mathrm{~m} / \mathrm{sec}$, respectively. These responses were strongly depressed or blocked after microinjections within the medullary subnucleus reticularis dorsalis of xylocaine or the NMDA antagonist MK-801. None of the VM/ neurons responded to innocuous cutaneous or proprioceptive stimuli. In contrast, all these neurons responded to noxious mechanical and thermal stimulation of the limbs and showed monotonic increases in their discharges to increasingly strong noxious cutaneous stimuli. In addition, some VM/ neurons were antidromically activated by stimulation in layer I of the dorsolateral frontal cortex. These findings suggest that the rat VM/ conveys and encodes cutaneous nociceptive inputs from any part of the body surface to layer I of the dorsolateral neocortex. This reticulo-thalamocortical network may allow any signal of pain to gain access to widespread areas of the neocortex and thus help prime the cortex for attentional reactions and/or the coordination of motor responses.

Key words: ventromedial thalamus; neocortex; brainstem reticular formation; pain; premotor, dorsal horn
Physiological studies of the roles of the thalamus in pain have assigned a sensory-discriminative role to ventrobasal regions but implicated medial areas in motivational-affective functions (Albe-Fessard et al., 1985; Bushnell, 1995; Lenz and Dougherty, 1997; Villanueva and Bernard, 1998). Recent functional imaging studies have shown that pain does much more than simply activate a "pain center" and involves a number of structures in the brain (Talbot et al., 1991; Casey et al., 1994; Derbyshire et al., 1997). Understanding this diversity probably requires the identification of the multiple neural systems responsible for pain processing.

Among these nociceptive systems, the reticulo-thalamic system is of particular interest because, in addition to nociceptive information being carried directly to the diencephalon by spinal pathways, some such information relays within the medullary reticular formation (Mehler et al., 1960). Widespread areas throughout the brainstem reticular formation contain neurons that are responsive to noxious stimuli. In contrast to other rostral brainstem reticular neurons that are relays of the nociceptive reticulo-thalamic pathways (Bowsher, 1976; Gebhart, 1982), there is a well delimited area in the caudalmost part of the rat medulla, the subnucleus reticularis dorsalis (SRD), which does not respond to heterosensory stimuli. The SRD contains neurons that respond exclusively to the activation of peripheral $\mathrm{A} \delta$ - and $\mathrm{C}$-fibers from any part of the body and encode the intensity of noxious cutaneous and visceral stimuli (Villanueva et al., 1996). Neurons with similar

Received May 14, 1999; revised July 6, 1999; accepted July 29, 1999.

This work was supported by the Institut National de la Santé et de la Recherche Médicale and l'Institut UPSA de la douleur. We are grateful to Dr. S. W. Cadden and R. Dallel for advice in the preparation of this manuscript, and to J. Martin, F. Roudier and R. Rambur for technical support.

Correspondence should be addressed to L. Villanueva, Institut National de la Santé et de la Recherche Médicale U-161, 2, Rue d'Alésia, 75014, Paris, France. Copyright (C) 1999 Society for Neuroscience 0270-6474/99/199063-10\$05.00/0 properties have also been recorded in this area in the monkey (Villanueva et al., 1990). Anatomical studies in the rat have shown that SRD projects densely to the lateral half of the ventromedial thalamus (VMl) (Villanueva et al., 1998).

The main afferents to the medial aspect of VM originate from deep cerebellar nuclei and the substantia nigra pars reticulata (Herkenham, 1979; Angaut et al., 1985; Deniau et al., 1994). Medial VM neurons project mainly to medial parts of layer I of the cortices, including the prelimbic and, to a lesser extent, the orbital areas of the prefrontal cortex (Jones and Leavitt, 1974; Herkenham, 1979, 1986; Arbuthnott et al., 1990; Deniau et al., 1994). In contrast, lateral (V M $l$ ) afferents terminate as a compact band in layer I of the rostralmost part of the dorsolateral frontal cortex. This projection most notably includes the motor cortex and, to a lesser extent, the dorsolateral orbital and more caudally the somatosensory cortices (Arbuthnott et al., 1990; Desbois and Villanueva, 1998).

It follows that the VM constitutes an interface between the medullary reticular formation, the cerebellum, the basal ganglia, and the cortex and thus is a heterogeneous area from both a functional and an anatomical point of view. The purpose of the present study was to investigate the somatosensory properties of VM neurons. We systematically recorded all the neurons in the VM and surrounding regions that responded to calibrated cutaneous stimuli. In an additional series of experiments, we investigated whether nociceptive responses in the $\mathrm{VM} l$ were relayed at the caudal medullary level. Finally, we tested whether VM $l$ neurons could be driven antidromically from the cortex.

Parts of this study has been published previously in abstract form (Monconduit et al., 1998).

\section{MATERIALS AND METHODS}

Animal preparation. All the animal experiments were approved by our local animal care committee and were in accordance with the guidelines 


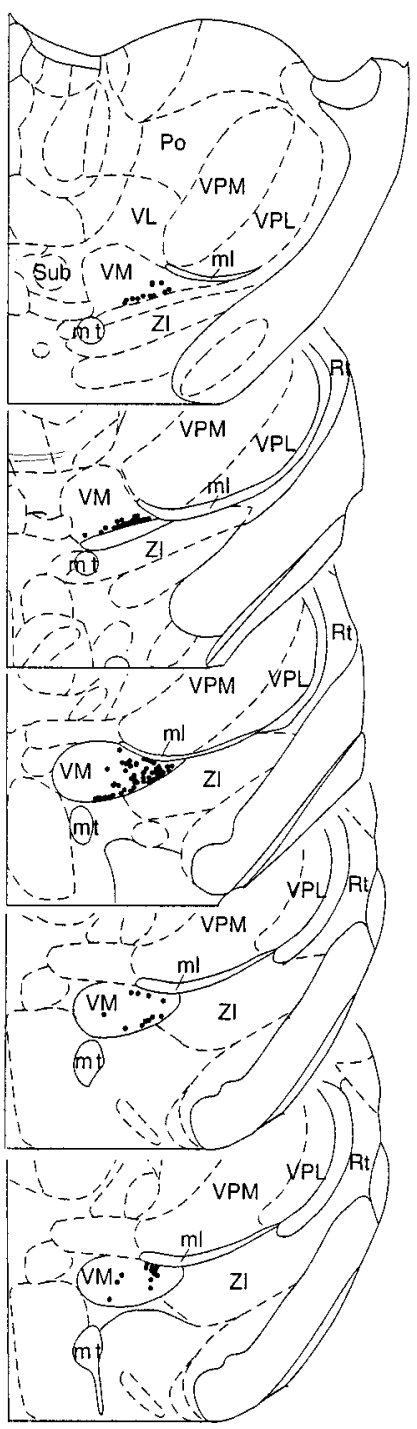

$-3.1$

$-3.6$

Figure 1. Rostrocaudal distribution of neurons recorded in the VM $(n=$ 135) that responded to noxious cutaneous stimuli. Each neuron is presented as a dot in a schematic representation of a coronal section of the diencephalon (Paxinos and Watson, 1997). Note that most of the units recorded were located in the $\mathrm{VM} l$ between -3.1 and $-3.8 \mathrm{~mm}$ with respect to bregma. $m l$, Medial lemniscus; $m t$, mammillothalamic tract; $R t$, reticular thalamic nucleus; Po, posterior thalamic nucleus; Sub, submedius thalamic nucleus; $V L$, ventrolateral thalamic nucleus; $V M$, ventromedial thalamic nucleus; $V P L$, ventroposterolateral thalamic nucleus; $V P M$, ventral posteromedial thalamic nucleus; $Z I$, zona incerta.

of the International Association for the Study of Pain. Electrophysiological experiments were performed on 147 male Sprague Dawley rats weighing 220-300 gm. The animals were deeply anesthetized with $2 \%$ halothane in a nitrous oxide/oxygen mixture (2:1). Cannulas were inserted into the trachea, a carotid artery, and a jugular vein. The animals were paralyzed by intravenous injection of gallamine triethiodide (10 $\mathrm{mg} / \mathrm{h}$; Rhône-Poulenc Rorer, Antony, France) and artificially ventilated at a rate of 52 strokes/min. The stroke volume was adjusted to maintain a normal acid-base equilibrium assessed using a capnometer (Capnomac II; Datex Instruments, Helsinki, Finland), which continuously measured respiratory frequency, end-tidal, inspired and expired $\mathrm{CO}_{2}(3.5-4.5 \%$ range), $\mathrm{O}_{2}(33 \%), \mathrm{N}_{2} \mathrm{O}(66 \%)$, and halothane levels via a catheter in the tracheal space. The measurements of $\mathrm{CO}_{2}$ and $\mathrm{N}_{2} \mathrm{O}$ were performed by infrared absorption and that of $\mathrm{O}_{2}$ levels by a fast paramagnetic analyzer. These parameters were displayed digitally, and each was under the control of an alarm. The vaporizer was adjusted with reference to these measurements.
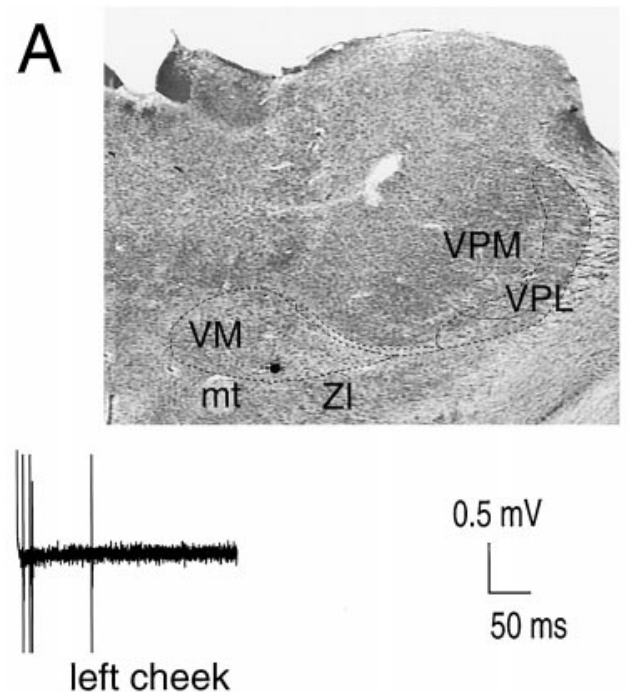

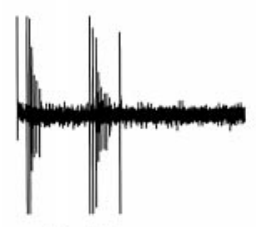

left forepaw
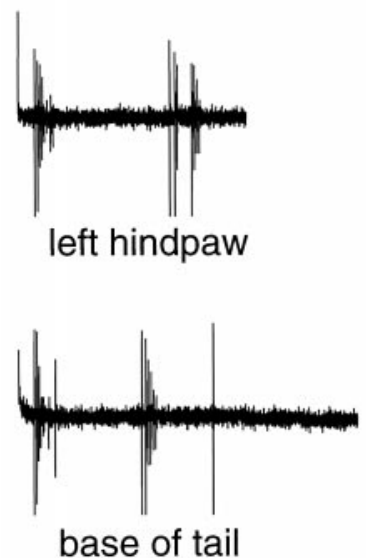

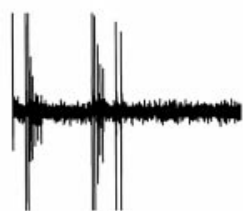

right forepaw

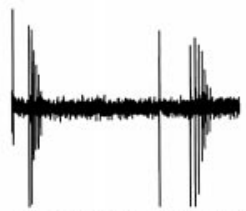

right hindpaw
Figure 2. Single-sweep recordings showing $\mathrm{A} \delta$ - and C-fiber-evoked responses of a $\mathrm{VM} l$ neuron (black dot in $A$ ) after supramaximal percutaneous electrical stimulation ( $2 \mathrm{msec}$ duration square-wave pulses) of different parts of the body (arrows). Note that the A $\delta$ - and $\mathrm{C}$-fiber responses were evoked from each area using an intensity of $10 \mathrm{~mA}$ for the paws, face, and base of the tail, and $15 \mathrm{~mA}$ for the tip of the tail. Same abbreviations in $A$ as in Figure 1.

The animals were mounted in a stereotaxic frame. The brain was exposed by a small craniectomy, and the dura mater was removed to allow access to the thalamus. After surgery, the level of halothane was reduced to $0.5-0.7 \%$. Mean systemic arterial blood pressure $(\sim 110$ $\mathrm{mmHg}$ ) was also continuously monitored. Core temperature was maintained at $37 \pm 0.5^{\circ} \mathrm{C}$ by means of a homeothermic blanket system.

Recordings. Unitary extracellular recordings were made using glass micropipette electrodes (10-15 $\mathrm{M} \Omega$ ) filled with a mixture of $5 \% \mathrm{NaCl}$ and pontamine sky blue dye. After amplification, action potentials were fed into a window discriminator and observed on an oscilloscope. Singleunit activity and blood pressure were digitized and monitored on-line using a data acquisition system (CED 1401 with Spike 2 software; Cambridge Electronic Design, Cambridge, UK). This allowed further processing and storage of the data on a Macintosh (Apple Computers, Cupertino, CA) computer. 


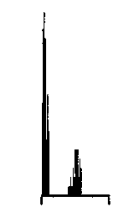

left cheek

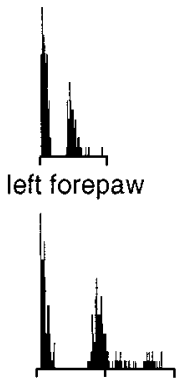

left hindpaw

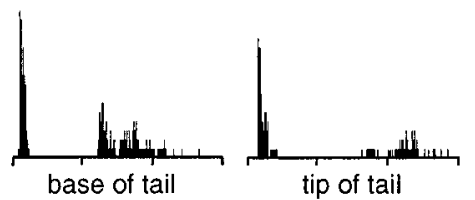

Figure 3. Individual example of cumulated responses of a $\mathrm{VM} l$ neuron to supramaximal percutaneous electrical stimulation of different parts of the body. Poststimulus histograms were built from the responses to $30 \mathrm{stim}-$ ulus presentations $(0.66 \mathrm{~Hz})$. The intensities were $15 \mathrm{~mA}$ for the tail and $10 \mathrm{~mA}$ for the paws and face. Note that (1) A $\delta$ - and $\mathrm{C}$-fiber-evoked responses were produced from all the areas stimulated, and (2) the differences in latencies of the responses evoked by stimulating the base and tip of the tail.

Microinjections. In these experiments, we tested the effects on $\mathrm{A} \delta$ - and $\mathrm{C}$-fiber-evoked responses of $\mathrm{VM} l$ neurons of microinjections within the SRD of xylocaine (2\%; AstraZeneca, Södertälje, Sweden) or an antagonist of the NMDA class of glutamate receptors, M K-801 (20 mM, $0.2 \mu \mathrm{l}$; Sigma, St. Louis, MO). These substances were injected at a rate of 0.8 $\mu \mathrm{l} / \mathrm{hr}$ using a geared syringe pump, which drove a Hamilton microliter syringe connected to a catheter glued to a micropipette. The glass micropipettes (35-50 $\mu \mathrm{m}$ in diameter) were positioned at an angle of $60^{\circ}$ to the horizontal plane, $1-1.5 \mathrm{~mm}$ caudal to the obex. This location was chosen because our previous electrophysiological observations had shown that this area contains SRD neurons with heterosegmental nociceptive convergence (Villanueva et al., 1988).
Antidromic responses to stimulation of the dorsolateral frontal cortex. Because $\mathrm{VM} l$ afferents terminate as a dense compact band especially in layer I of the rostralmost part of the dorsolateral frontal cortex (Desbois and Villanueva, 1998), stimulation in this area (negative square wave pulses of $0.2 \mathrm{msec}$ duration) was performed initially with two silver ball electrodes. In a later series, cortical stimulation was performed using a pair of aligned monopolar electrodes (exposed tip: $120 \mu \mathrm{m}$ in diameter, $150 \mu \mathrm{m}$ in length) (Rhodes Medical Instruments). These electrodes were inserted into the right side of the brain 4-5 mm rostral to bregma and 2-3 $\mathrm{mm}$ lateral to the midline. The two electrode tips, which were $600 \mu \mathrm{m}$ apart, could be stimulated independently. A large reference electrode was placed on the skull. Once a unit had been excited, the stimulation thresholds were measured for each of the two electrodes. The stimulation site with the lowest threshold was determined by stimulating at different depths and moving up to $1 \mathrm{~mm}$ lateral and medial to the site. Thereafter, the electrode was returned to the site of minimum threshold, and the current was doubled to test the criteria for antidromic activation, namely a response: (1) with a constant latency $(t<100 \mu$ sec variation) at a fixed stimulus intensity; (2) that could follow high-frequency stimulation (above $200 \mathrm{~Hz}$ ); and (3) that systematically collided with an orthodromic spike (spontaneous or evoked by peripheral stimulation) at an interval of less than $2 t+r$, where $t$ was the antidromic latency and $r$ the refractory period.

Experimental design. A systematic search for units responding to percutaneous electrical stimuli was performed at a depth of $6-8 \mathrm{~mm}$, in an area 3-4 mm caudal to bregma and 1-2.5 $\mathrm{mm}$ lateral to the midline (see the atlas of Paxinos and Watson, 1997). Low-intensity (1-3 mA) percutaneous electrical stimuli applied to the forepaws were used to help isolate unitary activity. Once a cell responded to electrical stimuli, the extent of its receptive field was determined through pairs of stainless steel stimulating electrodes inserted subcutaneously into the extremities of the limbs (toes 1 and 4 of the forepaws and toes 2 and 4 of the hindpaws) and the base or tip of the tail (proximal two-thirds, bilaterally). The stimulation sites on the tip and the base of the tail were always $100 \mathrm{~mm}$ apart.

The effects of the repeated application of increasing intensities of single 2 msec square-wave stimuli (30 trials, $0.66 \mathrm{~Hz}$ ) were analyzed using poststimulus histograms (PSH).

Responses to innocuous stimulation were determined using mechanical and proprioceptive stimulation of the limbs (air puffs, brushing, light pressure, rubbing, gentle stroking, and joints movements). Thereafter, responses to natural noxious stimuli were studied. Thermal stimulation consisted of $24 \mathrm{sec}$ periods of immersion of the extremities of the limbs in a hot $\left(40,44,48\right.$, and $\left.52^{\circ} \mathrm{C}\right)$ or cold $\left(-10,-5,0,5\right.$, and $\left.10^{\circ} \mathrm{C}\right)$ water bath. Mechanical stimulation consisted of calibrated pinches $(4,8,16,25$, and $32 \mathrm{~N} / \mathrm{cm}^{2}$ ) applied to the extremity of the limbs for $20 \mathrm{sec}$ with a forceps incorporating strain gauges connected to an amplifier (Hottinger Baldwin Messtechnik, Darmstadt, Germany).

As far as possible, all the noxious stimuli were tested for each individual cell but were not applied more frequently than once every $5 \mathrm{~min}$. When the neurons showed spontaneous activity, the level of this was subtracted from the total number of spikes observed during stimulation.

\begin{tabular}{|c|c|c|c|c|c|c|}
\hline & \multicolumn{3}{|c|}{$\mathrm{A} \delta$ Component } & \multicolumn{3}{|c|}{ C Component } \\
\hline & $\begin{array}{l}\text { Threshold } \\
(\mathrm{mA})\end{array}$ & $\begin{array}{l}\text { Latency } \\
(\mathrm{msec})\end{array}$ & $\begin{array}{l}\text { Spikes/stimulus } \\
\text { (for 3T) }\end{array}$ & $\begin{array}{l}\text { Threshold } \\
(\mathrm{mA})\end{array}$ & $\begin{array}{l}\text { Latency } \\
\text { (msec) }\end{array}$ & $\begin{array}{l}\text { Spikes/stimulus } \\
\text { (for 3T) }\end{array}$ \\
\hline \multicolumn{7}{|l|}{ Forepaw } \\
\hline Ipsilateral & $0.2 \pm 0.1$ & $13.9 \pm 0.6$ & $5.4 \pm 0.3$ & $1.6 \pm 0.3$ & $95.7 \pm 4.6$ & $4.6 \pm 0.5$ \\
\hline Contralateral & $0.2 \pm 0.1$ & $15.0 \pm 0.7$ & $5.1 \pm 0.3$ & $1.8 \pm 0.3$ & $97.4 \pm 4.7$ & $3.7 \pm 0.5$ \\
\hline \multicolumn{7}{|l|}{ Hindpaw } \\
\hline Ipsilateral & $0.3 \pm 0.1$ & $20.0 \pm 1.0$ & $5.9 \pm 0.4$ & $1.3 \pm 0.2$ & $166.6 \pm 7.8$ & $6.7 \pm 0.7$ \\
\hline Contralateral & $0.3 \pm 0.1$ & $21.6 \pm 1.0$ & $5.3 \pm 0.4$ & $1.8 \pm 0.4$ & $168.3 \pm 10.6$ & $3.9 \pm 0.5$ \\
\hline \multicolumn{7}{|l|}{ Tail } \\
\hline Base & $0.9 \pm 0.1$ & $24.0 \pm 1.2$ & $5.8 \pm 0.4$ & $4.3 \pm 0.8$ & $233.7 \pm 14.9$ & $4.7 \pm 0.6$ \\
\hline Tip & $0.9 \pm 0.2$ & $33.7 \pm 1.3$ & $4.8 \pm 0.4$ & $2.6 \pm 0.4$ & $363.7 \pm 15.9$ & $2.9 \pm 0.5$ \\
\hline
\end{tabular}

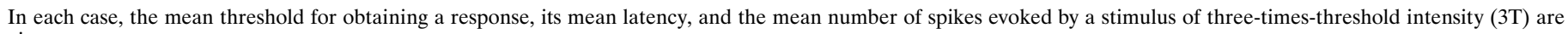
given. 

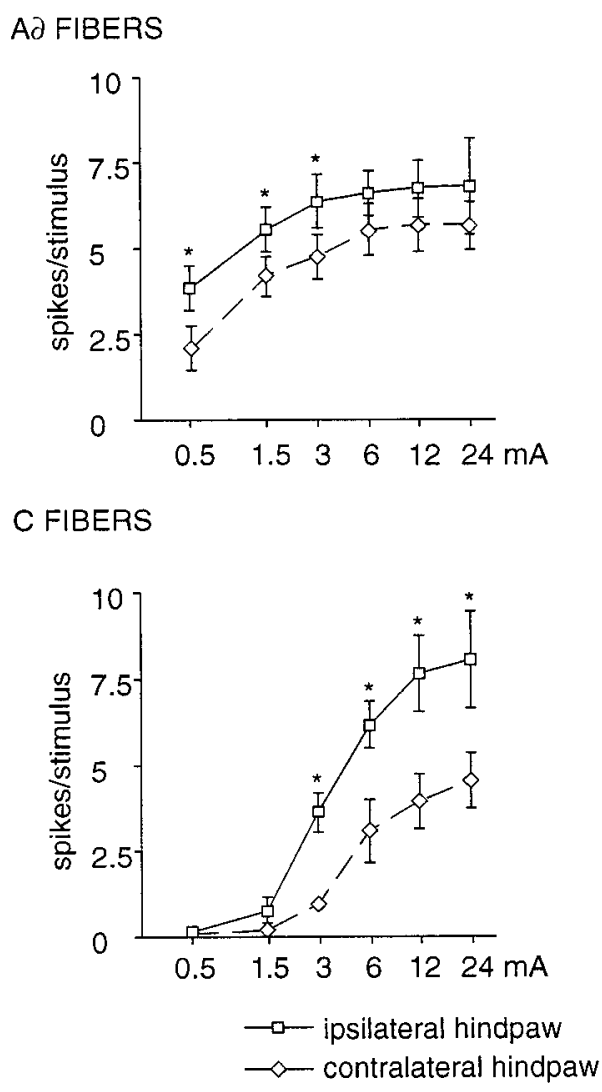

Figure 4. Mean magnitudes of $\mathrm{A} \delta$ - and $\mathrm{C}$-fiber-evoked responses from $\mathrm{VM} l$ neurons $(n=10)$ after percutaneous electrical stimulation of the hindpaws at different intensities. The stimulus-response relationships are represented as semilogarithmic plots (ordinate, magnitude of the responses; abscissa, stimulus current intensity). Note the linear relationship between the $\log$ of the intensity of the applied current and the magnitude of the $\mathrm{A} \delta$ - and $\mathrm{C}$-fiber responses in the 0.13-3.0 and $0.5-12 \mathrm{~mA}$ ranges, respectively, for the ipsilateral and contralateral hindpaws $(y=1.8 \log x+$ $1.5 ; p<0.0001 ; r_{8}=0.66 ; y=0.6 \log x+1.2 ; r_{8=} 0.68 ; p<0.0001$ for the ipsilateral hindpaws; and $y=1.5 \log x+0.8 ; r_{8}=0.69 ; p<0.0001 ; y=0.3$ $\log x+0.8 ; r_{8}=0.63 ; p<0.0001$ for the contralateral hindpaws). Note also that the responses of the $\mathrm{VM} l$ neurons were significantly larger after stimulation of the ipsilateral hindpaw $\left({ }^{*} p<0.05\right.$, corrected by Bonferroni procedure).

Only one cell was studied per animal, and these were always units that showed no alteration in spike amplitude or waveform during the entire experimental procedure.

Statistical analyses. The data were analyzed by Student's $t$ tests and nonlinear regression. The level of significance was set at $p<0.05$. For multiple comparisons, we applied ANOVAs with post hoc Bonferronicorrected $t$ tests; in cases in which three comparisons were performed, $p<0.05$ was chosen as the level of significance. For convenience, the results were expressed as mean \pm SEM.

Histological analysis. At the conclusion of the experiments, the recording sites and microinjections were marked by deposition of pontamine sky blue. After the animals had been killed by injection of a lethal dose of pentobarbital, the brains and medullas were removed and fixed in a $30 \%$ formalin solution for 1 week. The location of the stimulating electrodes in the cortex were marked by depositing iron at the tip of the electrode using 10 shocks $(200 \mathrm{msec}, 20 \mu \mathrm{A})$ with the electrode as the anode. In these cases, after the lethal dose of pentobarbital at the end of the experiment, the brain was removed and fixed for 3-5 d in a mixture of $8 \mathrm{vol}$ of $1 \%$ potassium ferricyanide in $10 \%$ formalin solution with $2 \mathrm{vol}$ of $2 \%$ acetic acid in 95\% alcohol (the Prussian blue reaction).

The samples were frozen, cut into serial $100-\mu \mathrm{m}$-thick sections, and stained with saffranin. Recording, microinjection, and stimulation sites were reconstructed by making camera lucida drawings of serial sections.
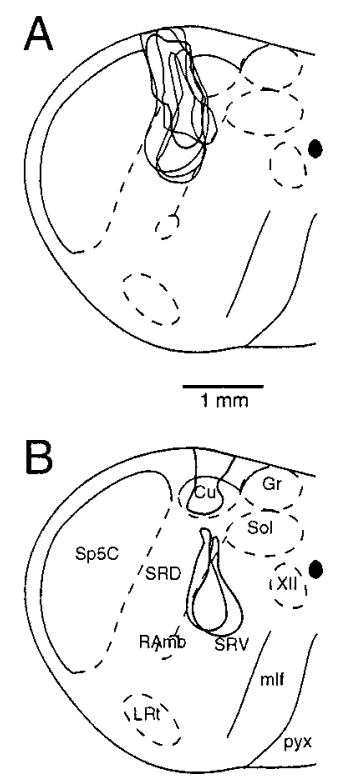

Figure 5. Summary of the histological findings from experiments during which the effects on the responses of $\mathrm{VM} l$ neurons of a microinjection of xylocaine into the caudal medulla were studied. $A$, Extents of the injection sites that depressed the responses of $\mathrm{VM} l$ neurons $(n=5)$. B. Extents of the injection sites that did not modify the responses of $\mathrm{VM} l$ neurons $(n=$ 3). $\mathrm{Cu}$, Cuneate nucleus; $\mathrm{Gr}$, gracile nucleus; $L R t$, lateral reticular nucleus; $m l f$, medial longitudinal fasciculus; $p y x$, pyramidal decussation; $R A m b$, retroambiguus nucleus; $S o l$, nucleus of the solitary tract; $S p 5 C$, trigeminal nucleus caudalis; $S R D$, subnucleus reticularis dorsalis; $S R V$, subnucleus reticularis ventralis; $X I I$, hypoglossal nucleus.

\section{RESULTS}

\section{General properties of the neurons}

A total of 135 units responding to cutaneous stimulation were recorded in an area 3.1-3.8 $\mathrm{mm}$ caudal to bregma and $1.4-2 \mathrm{~mm}$ lateral to the midline (Fig. 1). This region corresponds to the lateral half of the VM $l$. Most $(80 \%)$ of the $\mathrm{VM} l$ units exhibited spontaneous activity. The level of this spontaneous activity was highly variable and, even for a single cell, could change during the long periods of recording and could be followed by long periods of silence. Moreover, many (62\%) units developed afterdischarges after high intensity noxious stimulation.

\section{Responses of VM/ neurons to percutaneous electrical stimuli}

All the VMl cells that could be activated from the skin were excited by percutaneous electrical stimuli, no matter which part of the body was stimulated. As shown by the single-sweep recordings from an individual cell in Figure 2, the application of suprathreshold percutaneous electrical stimuli to the limbs elicited two peaks of activation at different but fixed latencies. This was invariably seen for all the $\mathrm{VM} l$ neurons studied. Although stimulation of the face was not tested systematically, two peaks of activation were also produced by such stimuli when they were applied (Figs. 2, 3). Both the single-sweep recordings (Fig. 2) and the PSHs (Fig. 3) showed that the two peaks were earlier when elicited from the base as opposed to the tip of the tail. The cumulative results revealed that, for the onset of the earlier peak of activation, the mean difference between the latencies obtained from the two sites of stimulation was $8.7 \pm 0.6 \mathrm{msec}$, which, taking into account the $100 \mathrm{~mm}$ between the sets of electrodes, corresponds to a peripheral conduction velocity of $12.9 \pm 0.9 \mathrm{~m} / \mathrm{sec}$. 

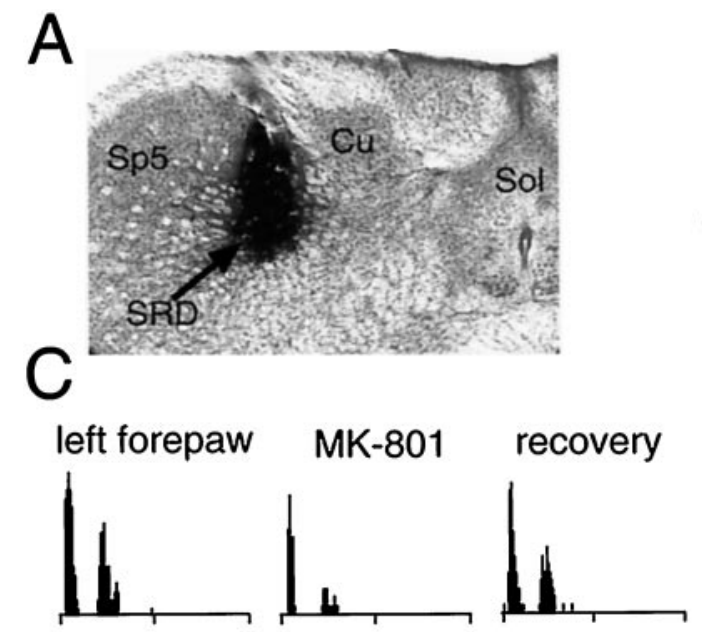

left hindpaw

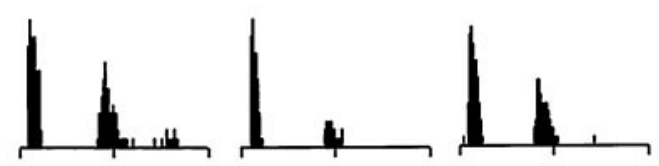

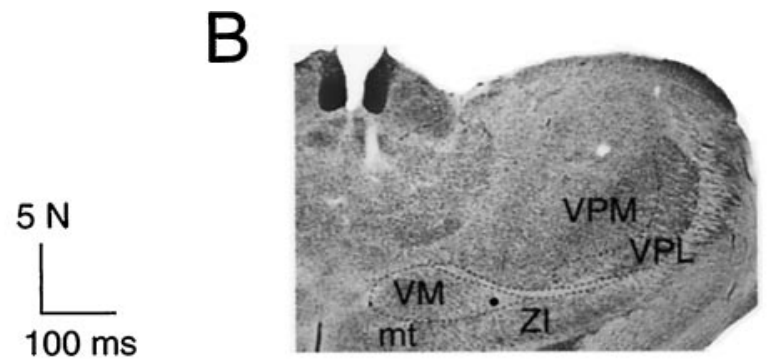

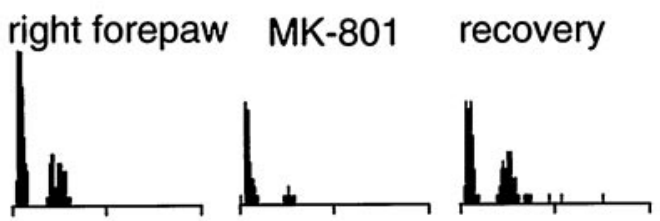

right hindpaw

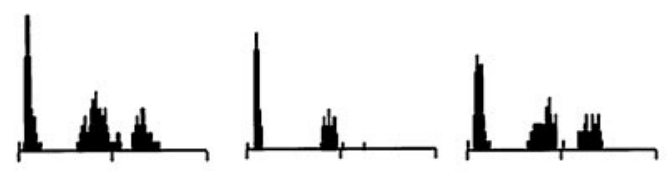

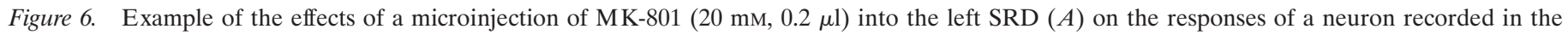

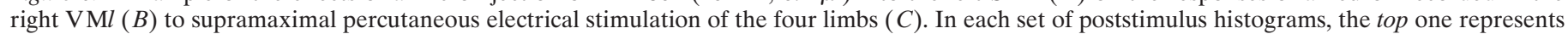

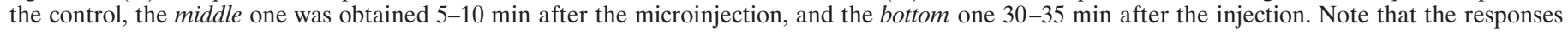
elicited from any limb were depressed by the microinjection. Abbreviations as in Figures 1 and 5 .

For the onset of the late peak of activation, the mean difference in latency from the base and tip of the tail was $129 \pm 14.7 \mathrm{msec}$, which corresponds to a peripheral conduction velocity of $1 \pm 0.2$ $\mathrm{m} / \mathrm{sec}$. According to Gasser and Erlanger (1927) and Burgess and Perl (1973), 12.9 and $1 \mathrm{~m} / \mathrm{sec}$ correspond to peripheral conduction velocities in the $\mathrm{A} \delta$ - and $\mathrm{C}$-fiber ranges, respectively. As shown in Figures 2 and 3, the latency distributions of C-fiber responses were frequently bimodal. Similar bimodal long-latency responses have been reported in spinal and medullary dorsal horns (Mendell, 1966; Dallel et al., 1998) and are probably caused by the activation of groups of $\mathrm{C}$-fibers with different conduction velocities. Table 1 summarizes the thresholds, latencies, and magnitudes of $\mathrm{A} \delta$ - and $\mathrm{C}$-fiber components of the responses evoked from different limbs. Note that the mean thresholds for obtaining A $\delta$-fiber components were restricted to the range of $0.2-0.3 \mathrm{~mA}$ for the paws but were higher $(\sim 0.8 \mathrm{~mA})$ for the tail $(p<0.0003)$. The C-fiber component could also be obtained at lower intensities $(1.5 \mathrm{~mA})$ from the paws than from the tail $(3 \mathrm{~mA} ; p<0.003)$. The magnitudes of the A $\delta$ responses from the different limbs were similar, whereas the $\mathrm{C}$-fiber responses were greater from the ipsilateral paws $(p<0.0001)$ and the base of the tail.

\section{Responses to graded electrical stimulation of the hindpaws}

All the $\mathrm{VM} l$ neurons responded to $\mathrm{A} \delta$ - and $\mathrm{C}$-fiber activation after suprathreshold percutaneous electrical stimulation of the extremities of the hindpaws. Responses to $\mathrm{A} \delta$ - and $\mathrm{C}$-fiber activation were obtained from the ipsilateral hindpaws with mean thresholds of 0.29 and $0.31 \mathrm{~mA}$, respectively; the corresponding values for the contralateral hindpaws were 1.5 and $3.0 \mathrm{~mA}$. At most stimulus intensities, the $\mathrm{A} \delta$ - and $\mathrm{C}$-fiber responses evoked from the ipsilateral hindpaw were significantly stronger than those from the contralateral hindpaw (Fig. 4). In addition, there were linear relationships between the log of stimulus intensity and the magnitude of the response in the $0.5-3$ and $1.5-24 \mathrm{~mA}$ ranges for the $\mathrm{A} \delta$ - and $\mathrm{C}$-fiber responses, respectively.

\section{Effects of blockade of the medullary SRD on the A $\delta$ - and $\mathrm{C}$-fiber activities of $\mathrm{VM} /$ neurons}

The above findings indicate that $\mathrm{VM} l$ neurons convey $\mathrm{A} \delta$ - and $\mathrm{C}$-fiber activities from whole body cutaneous receptive fields. Because these neurons are confined to a region receiving afferents from the contralateral SRD (Villanueva et al., 1998), we examined whether inactivation of this medullary structure could modify the responses of $\mathrm{VM} l$ neurons. A $\delta$-fiber responses were strongly depressed and $\mathrm{C}$-fiber responses were almost abolished after xylocaine injections confined to the dorsal part of the SRD (Fig. 5A). In these cases $(n=5)$, the maximum effect was obtained with a volume of $0.25 \mu \mathrm{l}$ of xylocaine; this depressed the A $\delta$ - and C-fiber responses by $76 \pm 11.5$ and $93 \pm 6.3 \%$, respectively $(p<0.02)$. In contrast, even volumes of $1 \mu$ l of xylocaine were unable to modify $\mathrm{VM} l$ responses when the injections were located in adjacent structures, such as the cuneate nucleus or the subnucleus reticularis ventralis $(101.8 \pm 16.2$ and $121 \pm 11.1 \%$ of control values for $\mathrm{A} \delta$ - and $\mathrm{C}$-fiber responses; respectively) (injection sites in Fig. 5B).

In a second series of experiments, both the $\mathrm{A} \delta$ - and $\mathrm{C}$-fiber responses of $\mathrm{VM} l$ neurons evoked from different areas of the body were strongly depressed after microinjections of the NMDA antagonist MK-801 into the SRD (Figs. 6, 7). The maximum effect was obtained with a volume of $0.2 \mu$ l. Injections of MK-801 into adjacent trigeminal structures or the subnucleus reticularis ventralis (Fig. 7B) did not modify $\mathrm{VM} l$ responses (Fig. 7D). In both series of experiments, blood pressure was unaffected by the microinjections. 


\section{A}

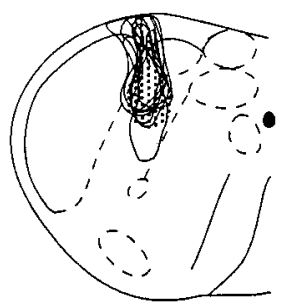

B

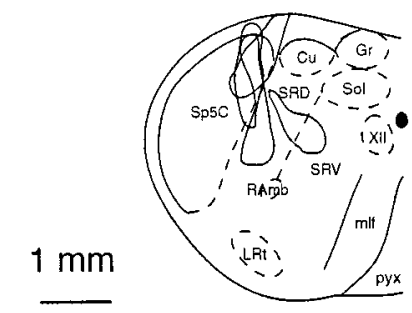

C
Ad Fibers

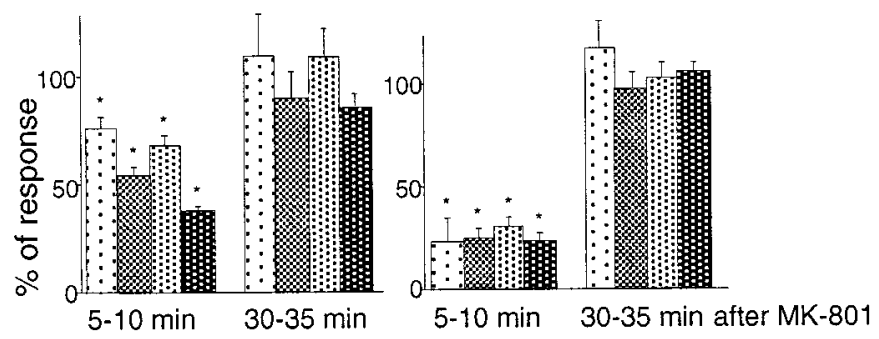

$\mathrm{D}$
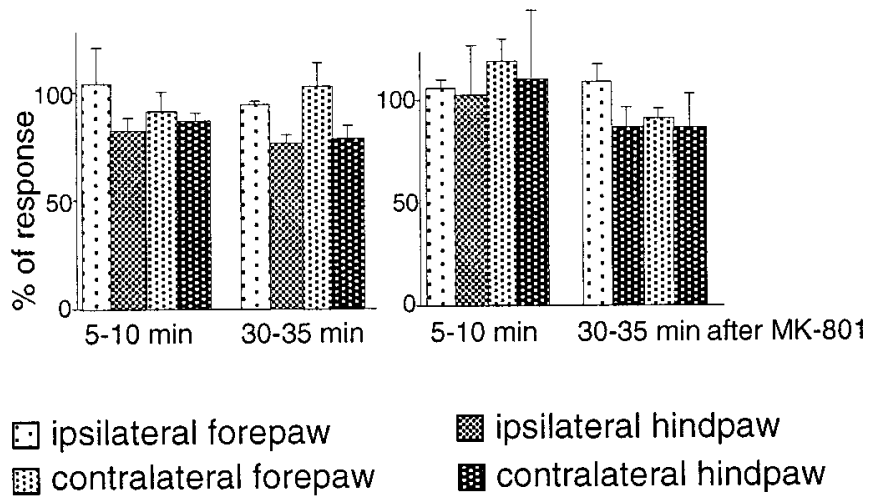

. ipsilateral hindpaw 目 contralateral hindpaw
Figure 7. Summary of the results from experiments during which the effects on the responses of $\mathrm{VM} l$ neurons of a microinjection of MK-801 in the caudal medulla were studied. $A$, Extent of the injection sites that depressed the responses of $\mathrm{VM} l$ neurons $(n=8)$. $B$, Extent of the injection sites that did not modify the responses of $\mathrm{VM} l$ neurons $(n=4)$. $C$, Mean results obtained when MK-801 was injected in the SRD (sites in $A$ ). $D$, Mean results obtained when MK- 801 was injected outside the SRD (sites in $B$ ). Results are expressed as percentages of control responses recorded before the microinjection $\left({ }^{*} p<0.05\right)$. Abbreviations as in Figure 5.

\section{Responses of VM/ neurons to natural stimuli}

All the $\mathrm{VM} l$ neurons that were excited from the skin did not respond to any innocuous stimuli, be it mechanical (brushing, rubbing, stroking) or thermal (temperatures $<44^{\circ} \mathrm{C}$ ). Furthermore, none of the $\mathrm{VM} l$ neurons responded to innocuous or noxious cold or to proprioceptive stimuli (joint movements). In contrast, all the $\mathrm{VM} l$ neurons responded to noxious natural stimuli (thermal or mechanical) when these were applied to cutaneous tissues anywhere on the body (Figs. 8, 9).
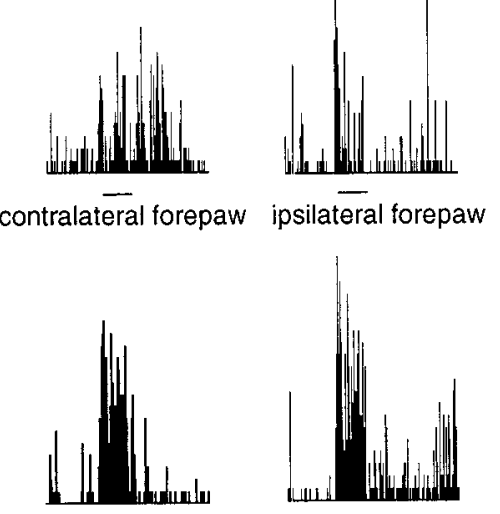

contralateral hindpaw ipsilateral hindpaw

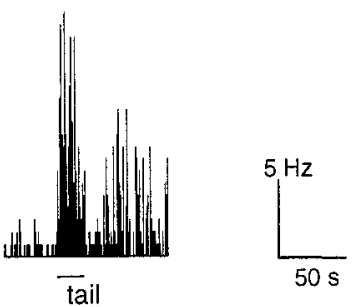

Figure 8. Activation of a VM $l$ neuron by a noxious mechanical stimulus $\left(32 \mathrm{~N} / \mathrm{cm}^{2}\right)$ applied for $20 \mathrm{sec}$ (bars) to different parts of the body. Note that, on some occasions, afterdischarges followed the cessation of stimulation.

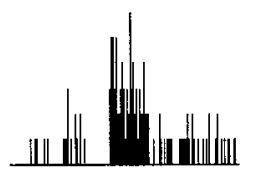

contralateral forepaw

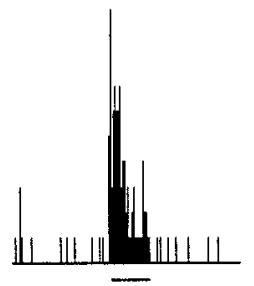

contralateral hindpaw

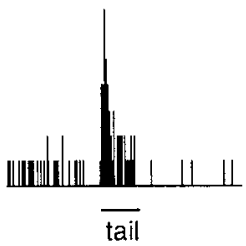

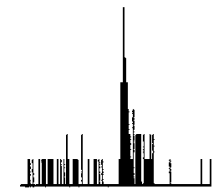

ipsilateral forepaw
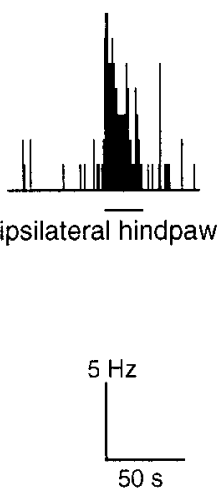

Figure 9. Activation of a $\mathrm{VM} l$ neuron by a noxious thermal stimulus $\left(48^{\circ} \mathrm{C}\right)$ applied for $24 \mathrm{sec}$ (bars) to different parts of the body.

\section{Responses of $\mathrm{VM} /$ neurons to graded natural stimulation of the ipsilateral hindpaw}

As shown in Figure 10, the VMl neurons had clear monotonic stimulus-response relationships after thermal or mechanical stimulation. A direct relationship can be seen between mechanical stimuli in the $4-32 \mathrm{~N} / \mathrm{cm}^{2}$ range and the number of action 

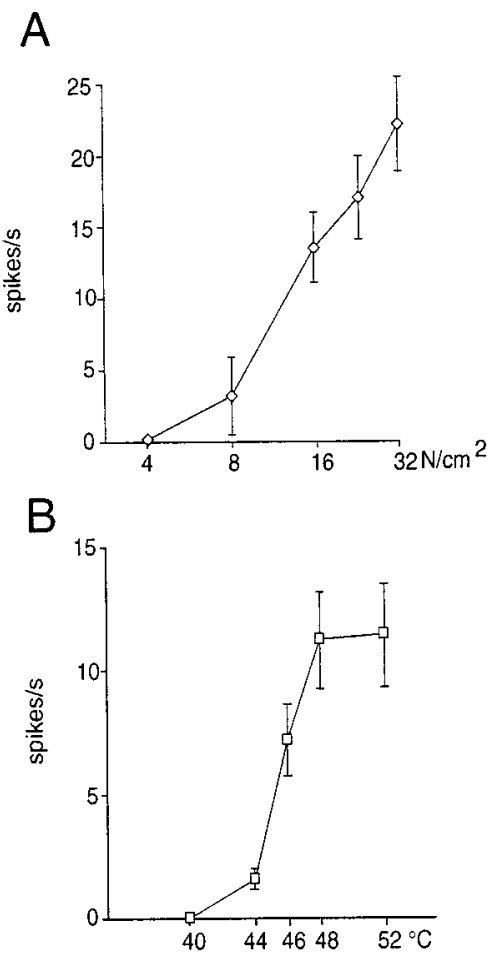

Figure 10. Cumulative results showing the magnitudes of the responses of $\mathrm{VM} l$ neurons to graded mechanical $(A ; n=7)$ or thermal $(B ; n=16)$ stimulation of the ipsilateral hindpaw. Note the linear relationship between the intensity within noxious ranges of both thermal $\left(44-48^{\circ} \mathrm{C}\right)$ and mechanical $\left(4-32 \mathrm{~N} / \mathrm{cm}^{2}\right)$ stimulation (abscissas) and the firing rate (ordinates) $(y=3.5 x-153.76 ; r=0.63 ; p<0.0009$; and $y=0.02 x-1.64$; $r=0.81 ; p<0.0001$, respectively).

potentials that were evoked (Fig. 10A). When graded thermal stimuli were applied, the $\mathrm{VM} l$ discharges increased monotonically within the range of $44-48^{\circ} \mathrm{C}$; beyond this, a plateau was observed (Fig. 10B).

\section{Responses of VM/ neurons to antidromic activation}

The use of antidromic activation demonstrated that $\mathrm{VM} l$ neurons relay nociceptive information toward the dorsolateral frontal cortex. As shown with an individual example in Figure $11 A$, the application of repetitive electrical stimuli to layer I of the frontal cortex produced a response with a constant latency. Repetitive stimulation (Fig. 11B) demonstrated that this response was capable of high-frequency following. Finally, the antidromic nature of the response was confirmed by the collision test (Fig. 11C). In fact, in all of 16 nociceptive units in the $\mathrm{VM} l$ that were studied in this way, the antidromic spikes followed high-frequency stimulation $(200-400 \mathrm{~Hz})$ and showed collision within the $2 t+r$ period. As shown in Table 2, the antidromic latencies were quite variable (3-20 msec) and, with a thalamo-cortical distance estimated as 14 $\mathrm{mm}$, corresponded to conduction velocities in the $0.7-4.7 \mathrm{~m} / \mathrm{sec}$ range. In addition, after monopolar microstimulation, lower thresholds for antidromic activation (50-400 $\mu \mathrm{A})$ were found when the stimulation electrodes were located at a depth of $108 \pm$ $13 \mu \mathrm{m}$ in the dorsolateral frontal cortex. Silent VMl units that did not respond to cutaneous stimulation could also be driven antidromically from the dorsolateral frontal cortex. However, all these units $(n=12)$ were located outside $\mathrm{VM} l$ at levels other than bregma $-3.6 ; 10$ of 12 were at bregma -3.1 to -3.4 , and 2 of 12

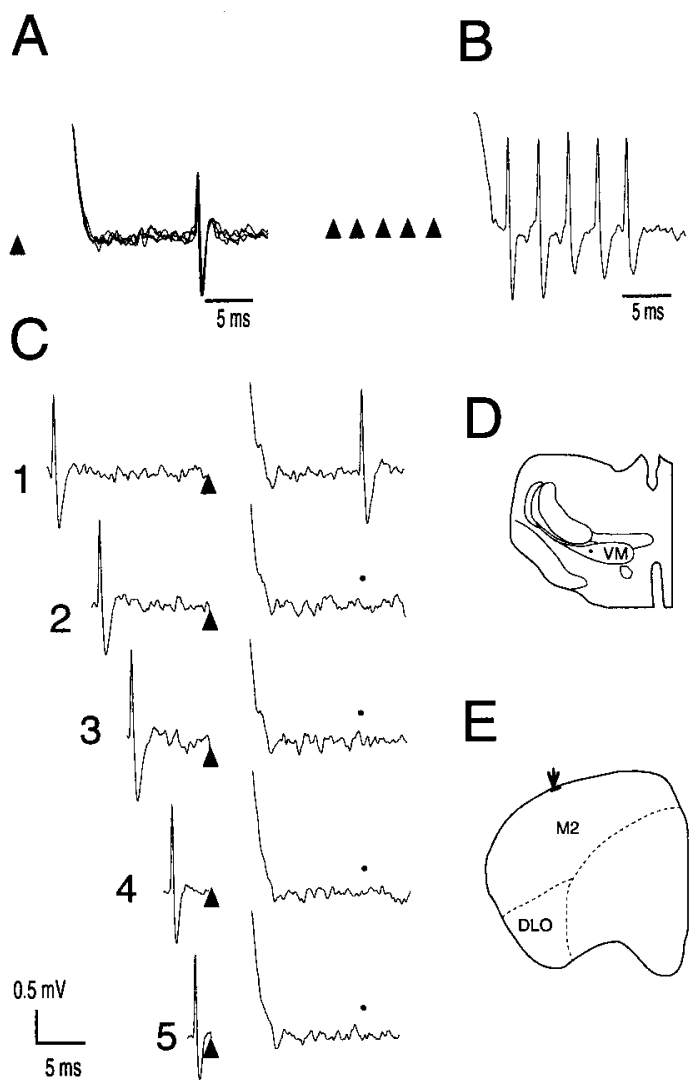

Figure 11. Antidromic activation of a $\mathrm{VM} l$ neuron from the cortex. $A$, Antidromic spikes. Note the overlapping of four antidromic spikes, indicating the stability of the latency of this response. $B$, High-frequency stimulation ( 5 pulses, $333 \mathrm{~Hz}$; timings indicated by triangles). Note the capacity of the antidromic response to follow this high frequency. C2-C5, Collision test. Filled circles show the expected timing of the antidromic spike if collision had not occurred. Note that, in $\mathrm{C} 1$, the antidromic spike appears at a latency of $20 \mathrm{msec}$, revealing the absence of collision when the orthodromic spike was outside the $2 t+r$ period. Triangles indicate the timing of the stimuli. $D$, Location of the recording site in the $\mathrm{VM} l$ at bregma -3.6. E, Location of the antidromic stimulation site in layer I of the dorsolateral anterior cortex at bregma 4.2.

were at bregma 3.8, i.e., mainly areas that were rostral to the $\mathrm{VMl}$ region in which the majority of nociceptive units were found.

\section{Blood pressure monitoring after calibrated cutaneous stimuli}

No significant modifications of blood pressure were observed after the application of repetitive suprathreshold percutaneous electrical or thermal stimuli between -10 and $44^{\circ} \mathrm{C}$. In contrast, cumulative data showed mean arterial blood pressure (113 \pm 3 $\mathrm{mmHg}$ ) increases of $25 \pm 12,42 \pm 4$, and $45 \pm 8 \%$ above the control values following 46,48 , and $52^{\circ} \mathrm{C}$, respectively. Moreover, only the strongest mechanical stimuli (16 and $32 \mathrm{~N} / \mathrm{cm}^{2}$ ) induced modifications of blood pressure, which were not unidirectional. These stimuli evoked increases, decreases, or no changes of blood pressure. As a whole, these findings suggest that, in our experimental conditions, the variations of blood pressure are not strictly dependent on the intensity of the cutaneous stimulation and that the discharges of $\mathrm{VM} l$ neurons and changes of blood pressure are independent phenomena.

\section{DISCUSSION}

This study shows that there is a population of neurons within the lateral part of the $\mathrm{VM} l$ that selectively conveys and encodes 


\begin{tabular}{|c|c|c|c|c|}
\hline \multicolumn{5}{|c|}{$\begin{array}{l}\text { Table 2. Characteris } \\
\text { electrical stimulation } \\
\text { surface electrodes or } \\
\text { Silver ball surface } \\
\text { stimulation }\end{array}$} \\
\hline $\begin{array}{l}\text { Threshold } \\
(\mu \mathrm{A})\end{array}$ & $\begin{array}{l}\text { Latency } \\
(\mathrm{msec})\end{array}$ & $\begin{array}{l}\text { Threshold } \\
(\mu \mathrm{A})\end{array}$ & $\begin{array}{l}\text { Latency } \\
\text { (msec) }\end{array}$ & $\begin{array}{l}\text { Depth } \\
(\mu \mathrm{m})\end{array}$ \\
\hline 800 & 3,2 & 120 & 9 & 110 \\
\hline 1700 & 8 & 180 & 10 & 120 \\
\hline 3200 & 10 & 400 & 8 & 110 \\
\hline 1500 & 9 & 400 & 14 & 90 \\
\hline 1500 & 6 & 50 & 11 & 130 \\
\hline 2000 & 14 & 200 & 8 & 110 \\
\hline \multirow[t]{3}{*}{2000} & 12 & 400 & 20 & 110 \\
\hline & & 50 & 9 & 90 \\
\hline & & 250 & 6 & 100 \\
\hline
\end{tabular}

In each case, the lowest threshold for obtaining a response and its latency are given. In the series of microstimulation, the corresponding depth is presented.

cutaneous nociceptive information from the whole body toward layer I of the anterior cortex. All the $\mathrm{VM} l$ neurons excited by stimulation of the skin were selectively activated by natural noxious stimuli, whereas other kinds of stimuli, be they innocuous, cutaneous, or proprioceptive, were ineffective.

\section{Peripheral cutaneous substrates responsible for the activation of $\mathrm{VM} /$ neurons}

The calculation of the differences in the latencies of responses elicited from the tip and base of the tail revealed that VMl neurons were exclusively driven by activities in $\mathrm{A} \delta$ - and $\mathrm{C}$-fibers. For obvious reasons, it was impossible to use the same procedure to estimate the conduction velocities of the peripheral fibers evoking the early and late responses from other areas of the body. However, the latencies of the two peaks of activation observed when stimulating the hindpaws or the forepaws were consistent with the activation of $\mathrm{A} \delta$ - and $\mathrm{C}$-fibers. In addition, our data suggest that $\mathrm{A} \delta$ - and $\mathrm{C}$-fiber cutaneous polymodal nociceptors have a prevalent role in the activation of $\mathrm{VM} l$ neurons in that they share several common features: (1) a monotonic increase in their responses to graded electrical and natural stimuli; (2) a linear relationship between the evoked firing rate and the intensities of both thermal and mechanical stimuli within noxious ranges (44$48^{\circ} \mathrm{C}$ and $4-32 \mathrm{~N} / \mathrm{cm}^{2}$, respectively); and (3) in some cases, the development of residual activity and/or afterdischarges after strong noxious stimulation.

\section{CNS substrates responsible for the activation of VMI neurons}

$\mathrm{VM}$-evoked discharges were not dependent on central mechanisms that mediate autonomic responses because they could be elicited by electrical or moderate natural noxious stimuli that did not elicit cardiovascular changes. Moreover, neither the increases nor the decreases in blood pressure that can be elicited by strong noxious stimuli were directly correlated to activity in $\mathrm{VM} l$ neurons in terms of their onset, magnitude, or duration.

There are several reasons to believe that nociceptive activity in the $\mathrm{VM} l$ arises primarily from monosynaptic inputs from the contralateral medullary SRD. Indeed, a strong reduction in VMl responses was obtained only when xylocaine or MK-801 injections were confined to the dorsal half of the contralateral SRD; injections into adjacent areas were without effect. When com- pared with MK-801, xylocaine injections induced stronger depressions of $\mathrm{VM} l$ activity. This difference could be caused by a widespread, local anesthetic action of xylocaine on both SRD neurons and their afferent inputs, whereas MK-801 acted in a more specific, restricted manner on the NMDA receptors of the SRD neurons. Another possibility is that some of the remaining activation was caused by either the activation of non-NMDA receptors or inputs from other ascending pathways.

In both series of experiments, the mean volume necessary for obtaining a maximum blockade of SRD-mediated activity was $\sim 0.2 \mu$ l. Theoretically, this volume corresponds to a sphere with a diameter of $\sim 700 \mu \mathrm{m}$ (volume of $4 / 3 \pi \mathrm{r}^{3}$ ), which is contained in the dorsal half of the SRD. This is obviously a mathematical calculation, which did not take into account the diffusion of the drug, but it corresponded approximately to the region labeled with pontamine. Interestingly, this medullary region is a principal target for afferents from the deep dorsal horn (Almeida et al., 1995; Raboisson et al., 1996), contains most of the SRD neurons with heterosegmental nociceptive convergence (Villanueva et al., 1988), and projects densely to the contralateral VM $l$ (Villanueva et al., 1998). A relevant role of contralateral SRD inputs in the activation of $\mathrm{VM} l$ neurons could also explain that $\mathrm{VM} l$ responses to ipsilateral stimuli were stronger, because the number of cells and magnitude of SRD responses increases when the opposite parts of the body are concerned (Villanueva et al., 1988).

\section{VMI neurons and the processing of nociceptive information}

The VM $l$ neurons were clearly activated by both $\mathrm{A} \delta$ - and $\mathrm{C}$-fibers. These responses increased monotonically, followed relatively high frequencies of stimulation, and were qualitatively similar to responses that have been recorded from neurons within the spinal and medullary dorsal horns and the SRD under similar experimental conditions (Villanueva et al., 1986, 1988). However, compared with SRD neurons, those in the $\mathrm{VM} l$ appear to be involved in a rather more complex processing of noxious inputs in that they showed an even higher degree of convergence. This was evidenced by the following: (1) their lower thresholds for showing $\mathrm{A} \delta$ - and $\mathrm{C}$-fiber evoked responses; and (2) the fact that all VM $l$ neurons showed $\mathrm{A} \delta$ - and $\mathrm{C}$-fiber responses, no matter which part of the body was stimulated. $\mathrm{VM} l$ neurons could have different synaptic properties, as illustrated by their less steep slopes for the stimulus-response relationships (two to four times less than those for SRD units). This last difference could also be related to a direct, stronger effect of the general anesthetics at upper thalamic levels than at a medullary level. Another possibility lies in the occurrence of several modulatory mechanisms acting directly or indirectly at the thalamic level. For instance, indirect mechanisms triggered by peripheral inputs can modulate the SRD output (Villanueva et al., 1994). These modulatory mechanisms could be strengthened by additional inhibitory processes acting directly at the thalamic level, e.g., those mediated by intrathalamic or corticofugal inputs (Crabtree et al., 1998; Rauscheker, 1998).

To the best of our knowledge, a selective activation of $\mathrm{VM} l$ neurons by both $\mathrm{A} \delta$ - and $\mathrm{C}$-fibers from any part of the body has not been reported before, probably because most previous electrophysiological studies were devoted to areas receiving cerebellar or nigral afferent inputs, which terminate mainly in VM areas medial and/or rostral to its nociceptive part (Herkenham, 1979; Angaut et al., 1985; Deniau et al., 1994). It is possible that the silent units that were recorded in our study and were unresponsive to cutaneous stimuli were driven by cerebellar or nigral afferents, 
because they were located in the rostral VM and nigral influences are mainly inhibitory (MacLeod et al., 1980; MacLeod and James, 1984; Deniau and Chevalier, 1985).

Some electrophysiological studies in rats have recorded units responsive to noxious stimulation in both the VM (Dostrovsky and Guilbaud, 1990) and the area immediately ventral to the ventroposterolateral thalamic nucleus (VPL) (Berkley et al., 1993). Interestingly, the units located ventrally to the VPL, in the area in which SRD terminals are located, showed a greater amount of cutaneous and visceral nociceptive convergence than did those recorded within the VPL (Berkley et al., 1993). Although differences in cytoarchitecture make it difficult to establish analogies with data obtained from other species, several reports have shown that nociceptive units in the cat ventral thalamus are located particularly in the periphery of the ventrobasal complex (Honda et al., 1983; Knifki and Vahle-Hinz, 1987; Yokota et al., 1988; Yen et al., 1991). Moreover, a large proportion of neurons responding to noxious stimuli were recorded in the inferior part of the ventral posterior thalamic complex in the monkey (Apkarian and Shi, 1994). However, most of the nociceptive units recorded in these studies had restricted receptive fields, contrasting with the whole body receptive fields of rat $\mathrm{VM} l$ neurons.

Floyd et al. (1996) have shown that the rat VM receives ipsilateral projections from the ventrolateral periaqueductal gray and can be delimited by calbindin immunoreactivity. They suggested that this region could be homologous to the posterior part of the ventromedial nucleus (VMpo) in the monkey because the VMpo is also calbindin-positive and most of its neurons are specifically nociceptive or thermoreceptive (Craig et al., 1994). However, additional data will be required to establish clearly whether such an analogy exists, because cortical projections from the VMpo terminate mainly in the middle layers of the agranular insula in monkeys (Craig et al., 1994), whereas the VM in the rat projects almost exclusively to layer I (Herkenham, 1979, 1986; Arbuthnott et al., 1990; Deniau et al., 1994; Desbois and Villanueva, 1998). In addition, the rat VM does not receive direct spinothalamic afferent inputs, and its nociceptive units, unlike VMpo neurons (Craig, 1995), do not have restricted receptive fields or respond to noxious cold stimuli.

\section{Conclusions}

Our findings suggest that V $\mathrm{M} l$ neurons relay widespread nociceptive inputs from the medullary reticular formation to the whole of layer I of the dorsolateral neocortex. Interestingly, in all mammals, including man, the pyramidal cell (the main output neuron in the neocortex) invariably has its apical dendrites oriented to the pial surface and contacts layer I (Ramon y Cajal, 1972; Marín-Padilla, 1998). Thus, the $\mathrm{VM} l$ may constitute an important thalamic branch of what was originally termed the "ascending reticular activating system" (Morison and Dempsey, 1942; Moruzzi and Magoun, 1949; Jasper, 1961; Herkenham, 1986). In this respect, it is interesting that numerous functional imaging studies have suggested that pain is an obvious candidate for producing widespread cortical activation (Talbot et al., 1991; Casey et al., 1994; Derbyshire et al., 1997). Moreover, it has been shown that the responses of rat thalamo-cortical VM neurons are dependent on the state of arousal of the animal (MacLeod and James, 1984), and stimulation of VM neurons in the cat causes depolarization of cortical layer I cells and elicits recruiting responses in the anterior cortex (Glenn et al., 1982). Our findings could provide an anatomical and functional basis for any signal of cutaneous pain to alter cortical activity in a universal way, namely by contacting the distal ends of apical dendrites of pyramidal cells in layer I. This would be consistent with the original proposal of Herkenham (1986).

\section{REFERENCES}

Albe-Fessard D, Berkley KJ, Kruger L, Ralston HJ, Willis WD (1985) Diencephalic mechanisms of pain sensation. Brain Res Rev 9:217-296.

Almeida A, Tavares I, Lima D (1995) Projection sites of superficial or deep dorsal horn in the dorsal reticular nucleus. NeuroReport 6:1245-1248.

Angaut P, Cicirata F, Serapide MF (1985) Topographic organization of the cerebellothalamic projections in the rat. An autoradiographic study. Neuroscience 15:389-401.

Apkarian AV, Shi T (1994) Squirrel monkey lateral thalamus. Somatic nociresponsive neurons and their relation to spinothalamic terminals. J Neurosci 14:6779-6795.

Arbuthnott GW, Mac Leod NK, Maxwell DJ, Wright AK (1990) Distribution and synaptic contacts of the cortical terminals arising from neurons in the rat ventromedial thalamic nucleus. Neuroscience 38:47-60.

Berkley KJ, Guilbaud G, Benoist JM, Gautron M (1993) Responses of neurons in and near the thalamic ventrobasal complex of the rat to stimulation of uterus, cervix, vagina, colon, and skin. J Neurophysiol 69:557-568.

Bowsher D (1976) Role of the reticular formation in responses to noxious stimulation. Pain 2:361-378.

Burgess PR, Perl ER (1973) Cutaneous mechanoreceptors and nociceptors. In: Handbook of sensory physiology. Somatosensory system (Iggo A, ed), pp 29-78. Berlin: Springer.

Bushnell MC (1995) Thalamic processing of sensory-discriminative and affective-motivational dimensions of pain. In: Forebrain areas involved in pain processing (Besson JM, Guilbaud G, Ollat H, eds), pp 63-77. Paris: Libbey.

Casey KL, Minoshima S, Berger KL, Koeppe RA, Morrow TJ, Frey KA (1994) Positron emission tomographic analysis of cerebral structures activated specifically by repetitive noxious heat stimuli. J Neurophysiol 71:802-807.

Crabtree J, Collingridge GL, Isaac JTR (1998) A new intrathalamic pathway linking modality-related nuclei in the dorsal thalamus. Nat Neurosci 1:389-394.

Craig AD (1995) Supraspinal projections of lamina I neurons. In: Forebrain areas involved in pain processing (Besson JM, Guilbaud G, Ollat H, eds), pp 13-25. Paris: Libbey.

Craig AD, Bushnell MC, Zhang ET, Blomqvist A (1994) A thalamic nucleus specific for pain and temperature sensation. Nature 372:770-773.

Dallel R, Dualé C, Molat, JL (1998) Morphine administered in the substantia gelatinosa of the spinal trigeminal nucleus caudalis inhibits nociceptive activities in the spinal trigeminal nucleus oralis. J Neurosci 18:3529-3536.

Deniau JM, Chevalier G (1985) Disinhibition as a basic process in the expression of striatal functions. II. The striato-nigral influence on thalamocortical cells of the ventromedial thalamic nucleus. Brain Res 334:227-233.

Deniau JM, Menétrey A, Thierry AM (1994) Indirect nucleus accumbens input to the prefrontal cortex via the substantia nigra pars reticulata: a combined anatomical and electrophysiological study in the rat. Neuroscience 61:533-545.

Derbyshire SWG, Jones AKP, Gyulai F, Clark S, Townsend D, Firestone LL (1997) Pain processing during three levels of noxious stimulation produces differential patterns of central activity. Pain 73:431-445.

Desbois C, Villanueva L (1998) Cortical projections from the ventromedial thalamic nucleus in rats: a study of the reticulo-thalamo-cortical nociceptive system. Forum Eur Neurosci Abstr 22:155.

Dostrovsky JO, Guilbaud G (1990) Nociceptive responses in medial thalamus of the normal and arthritic rat. Pain 40:93-104.

Floyd N, Keay KA, Bandler R (1996) A calbindin immunoreactive "deep pain" recipient thalamic nucleus in the rat. NeuroReport 7:622-626.

Gasser HS, Erlanger J (1927) The role played by the sizes of the constituent fibers of a nerve trunk in determining the form of its action potential wave. Am J Physiol 80:522-547.

Gebhart GF (1982) Opiate and opioid peptide effects on brain stem 
neurons: relevance to nociception and antinociceptive mechanisms. Pain 12:93-140.

Glenn LL, Hada J, Roy JP, Deschênes M, Steriade M (1982) Anterograde tracer and field potential analysis of the neocortical layer I projection from nucleus ventralis medialis of the thalamus in cat. Neuroscience 7:1861-1877.

Herkenham M (1979) The afferent and efferent connections of the ventromedial thalamic nucleus in the rat. J Comp Neurol 183:487-518.

Herkenham M (1986) New perspectives on the organization and evolution of nonspecific thalamocortical projections. In: Cerebral cortex, Vol 5, Sensory-motor areas and aspects of cortical connectivity (Jones EG, Peters A, eds), pp 403-445. New York: Plenum.

Honda CN, Mense S, Perl E (1983) Neurons in ventrobasal region of cat thalamus selectively responsive to noxious mechanical stimulation. J Neurophysiol 49:662-673.

Jasper HH (1961) Thalamic reticular system. In: Electrical stimulation of the brain (Sheer DE, ed), pp 277-287 Austin, TX: University of Texas.

Jones EG, Leavitt RY (1974) Retrograde axonal transport and the demonstration of non-specific projections to the cerebral cortex and striatum from thalamic intralaminar nuclei in the rat, cat and monkey. J Comp Neurol 154:349-378.

Knifki KD, Vahle-Hinz C (1987) The periphery of the cat's ventroposterolateromedial nucleus (VPMp): nociceptive neurones. In: Thalamus and pain (Besson JM, Guilbaud G, Peschanski M, eds), pp 245-257. Amsterdam: Excerpta Medica.

Lenz FA, Dougherty PM (1997) Pain processing in the human thalamus. In: Thalamus: experimental and clinical aspects (Steriade M, Jones EG, McCormick DA, eds), pp 617-651. New York: Elsevier.

MacLeod NK, James TA (1984) Regulation of cerebello-cortical transmission in the rat ventromedial thalamic nucleus. Exp Brain Res 55:535-552.

MacLeod NK, Kilpatrick IC, Starr MS (1980) Evidence for a GABAergic nigrothalamic pathway in the rat. II. Electrophysiological studies. Exp Brain Res 40:55-61.

Marín-Padilla M (1998) Cajal-Retzius cells and the development of the neocortex. Trends Neurosci 21:64-71.

Mehler WR, Feferman ME, Nauta WJH (1960) Ascending axon degeneration following antero-lateral corodotomy, an experimental study in the monkey. Brain 83:718-751.

Mendell LM (1966) Physiological properties of unmyelinated fiber projection to the spinal cord. Exp Neurol 16:316-332.

Monconduit L, Bourgeais L, Bernard JF, Le Bars D, Villanueva L (1998) Convergence of heterotopic nociceptive information onto ventromedial thalamic neurons in rats. Soc Neurosci Abstr 24:1129.

Morison RS, Dempsey EW (1942) A study of thalamo-cortical relations. Am J Physiol 135:281-292.

Moruzzi G, Magoun HW (1949) Brain stem reticular formation and activation of the EEG. Electroencephalogr Clin Neurophysiol 1:445-473.

Paxinos G, Watson C (1997) The rat brain in stereotaxic coordinates, Ed 3. New York: Academic.

Raboisson P, Dallel R, Bernard JF, Le Bars D, Villanueva L (1996) Organization of efferent projections from the spinal cervical enlargement to the medullary subnucleus reticularis dorsalis and the adjacent cuneate nucleus: a PHA-L study in the rat. J Comp Neurol 367:503-517.

Ramon y Cajal, S (1972) Histologie du Système Nerveux de l'Homme et des Vertébrés, Vol I and II. Madrid: Instituto Ramon y Cajal. [Reprinted from the original (1911). Paris: Maloine.]

Rauscheker JP (1998) Cortical control of the thalamus: top-down processing and plasticity. Nat Neurosci 1:179-180.

Talbot JD, Marret S, Evans AC, Meyer E, Bushnell MC, Duncan GH (1991) Multiple representations of pain in human cerebral cortex. Science 251:1355-1358.

Villanueva L, Bernard JF (1998) The multiplicity of ascending pain pathways. In: Handbook of behavioral state control. Cellular and molecular mechanisms (Lydic R, Baghdoyan HA, eds), pp 569-585. Boca Raton, FL: CRC.

Villanueva L, Chitour D, Le Bars D (1986) Involvement of the dorsolateral funiculus (DLF) in the descending spinal projections responsible for diffuse noxious inhibitory controls in the rat. J Neurophysiol 56:1185-1195.

Villanueva L, Bouhassira D, Bing Z, Le Bars D (1988) Convergence of heterotopic nociceptive information onto subnucleus reticularis dorsalis neurons in the rat medulla. J Neurophysiol 60:980-1009.

Villanueva L, Cliffer KD, Sorkin L, Le Bars D, Willis WD (1990) Convergence of heterotopic nociceptive information onto neurons of the caudal medullary reticular formation in the monkey (Macaca fascicularis). J Neurophysiol 63:1118-1127.

Villanueva L, Bing Z, Le Bars D (1994) Effects of heterotopic noxious stimuli on activity of neurones in subnucleus reticularis dorsalis in the rat medulla. J Physiol (Lond) 475:255-266.

Villanueva L, Bouhassira D, Le Bars D (1996) The medullary subnucleus reticularis dorsalis (SRD) as a key link in both the transmission and modulation of pain signals. Pain 67:231-240.

Villanueva L, Desbois C, Le Bars D, Bernard JF (1998) Organization of diencephalic projections from the medullary subnucleus reticularis dorsalis and the adjacent cuneate nucleus: a retrograde and anterograde tracer study in the rat. J Comp Neurol 390:133-160.

Yen CT, Honda CN, Jones EG (1991) Electrophysiological study of spinothalamic inputs to ventrolateral and adjacent thalamic nuclei of the cat. J Neurophysiol 66:1033-1047.

Yokota T, Asato F, Koyama N, Masuda T, Taguchi H (1988) Nociceptive body representation in nucleus ventralis posterolateralis of cat thalamus. J Neurophysiol 60:1714-1727. 